\title{
Complex in situ bioremediation of upper aquifers near the uranium sludge depository
}

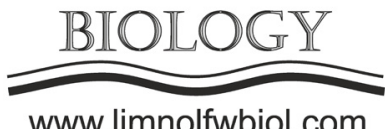

www.limnolfwbiol.com

\author{
Safonov A.V. ${ }^{1,2}$, Popova N.M. ${ }^{1}$, Ershov N.A. ${ }^{1}$, Artemiev G.D. ${ }^{1}$, Buslaeva P.A. ${ }^{1}$, \\ Boguslavskiy A.E . ${ }^{3}$
}

\author{
${ }^{1}$ A.N. Frumkin Institute of Physical chemistry and Electrochemistry of the Russian academy of sciences, 40 Obruchev street, Moscow, \\ 117342 Russia \\ ${ }^{2}$ Nuclear Safety Institute of the Russian Academy of Sciences (IBRAE), 52 Bolshaya Tulskaya Street, Moscow, 115191, Russia \\ ${ }^{3}$ V.S. Sobolev Institute of Geology and Mineralogy of the Russian Academy of Sciences (IGM SB RAS) 3 Ac. Koptyuga ave., \\ Novosibirsk, Russia, 630090.
}

\begin{abstract}
The goal of the study was to investigate the microbial community in the groundwater with high nitrate concentration of a suspended surface uranium sludges repositories (Siberia, Russia) and to determine the possibility of in situ groundwater bioremediation.
\end{abstract}

Keywords: uranium, nitrate, ammonium sulphate pollution, bioremediation, sludge depository

In this study the biochemical reduction of both nitrate and sulfate in U-containing aquifers of the Zelenogorsk Electrochemical Plant (ZEP) and Angarsk electrochemical plant have been investigated experimentally and thermodynamically. Sludge depositories where built in 1960s and it is still in use. Uranium concentration in subsurface water in several zones reached 1-2 $\mathrm{mg} / \mathrm{l}$, the total nitrate concentration -up to $10000 \mathrm{mg} / \mathrm{l}$, sulfates $-3000 \mathrm{mg} / \mathrm{l}$. Uranium transport in subsurface water depends on geochemical properties of the aquifer: sorption capacity of the rocks, TOC, Eh, oxidizers concentration $\left(\mathrm{O}_{2}, \mathrm{NO}_{3}, \mathrm{Fe}^{3+}\right.$ etc. $)$ and biogeochemical processes.

We have studied chemical and microbiological characteristics of water samples in polluted and non polluted areas and got main data for biogeochemical modelling of Uranium migration capacity. We have found active microbial community with domination of aerobic organotrophic, denitrifying, sulphatereducing and iron reducing bacteria. High-throughput sequencing of the V3-V4 region of the 16S rRNA gene revealed the presence of members of the phyla Proteobacteria (genera Pseudomonas, Brevundimonas, Acidovorax, Desulfovibrio), Firmicutes (genera Bacillus and Sporosarcina), and Actinobacteria (Nocardia) (Table). Groundwater samples contained culturable aerobic organotrophic, as well as anaerobic fermenting, iron-reducing, and denitrifying bacteria. Members of the genera Pseudomonas, Rhizobium, Brevundimonas, Acidovorax, Desulfovibrio were capable of reducing nitrate to molecular nitrogen.
In laboratory experiments we have studied the possibility and some technical aspects of aquifers in situ bioremediation process by organic compounds injection.

It was observed that $E h$ decrease up to $-300 \mathrm{mV}$ has a distinct effect on the denitrification and uranium precipitation as $\mathrm{UO}_{2}(\mathrm{~s})$. Nitrate was reduced to $\mathrm{N}_{2}$ with a temporary accumulation of the intermediate nitrite. According to the X-ray fluorescence analysis and thermodynamic calculations, all uranium is deposited as $\mathrm{UO}_{2+\mathrm{x}}$ oxides, together with the sulfides in the reducing environment. We found the most important microbiological process for Uranium immobilization is the oxigen consumption in bacterial respiration processes. After that redox-dependent uranium reduction can be expected. In the presence of sulfate ions, further anaerobic processes of microbial sulfate reduction and iron reduction lead to formation of iron sulphide, which plays a significant role as an antioxidant buffer in case of dissolved oxygen migration (Bargar et al., 2013).

Thus, biotic sulfatereduction leads to formation of iron sulphidic phases, forming the sulphidic reductive barrier that has buffer properties to oxidation (Kelly et al., 2008). This barrier can be considered as an antimigration barrier for metals and radionuclides. Thus, microbial stimulation would be a promising low-cost and easy-to-use technology for purification of underground aquifers of nitrogen compounds and immobilization of uranium in insoluble forms (Li et al., 2009). 
Table. Microbial communities of water samples collected near AEP and ZEP 16S RNA genes profiles

\begin{tabular}{|c|c|c|c|c|c|c|c|}
\hline \multicolumn{4}{|c|}{ AEP } & \multicolumn{4}{|c|}{ ZEP } \\
\hline \multicolumn{8}{|c|}{$\mathrm{C} \mathrm{NO}_{3}^{-} \mathrm{mg} / \mathrm{l}$} \\
\hline \multicolumn{2}{|l|}{11200} & \multicolumn{2}{|l|}{2300} & \multicolumn{2}{|l|}{15200} & \multicolumn{2}{|l|}{2100} \\
\hline Acidovorax & 19 & Pseudomonas & 11 & Desulfovibrio & 47 & Desulfovibrio & 33 \\
\hline Curvibacter & 7 & Lysobacter & 7 & Aquamicrobium & 1 & Ensifer & 2 \\
\hline Rhodoferax & 4 & Luteimonas & 1 & Bacteroides & 3 & Roseiarcus & 1 \\
\hline Ramlibacter & 2 & Arenimonas & 1 & Prevotella & 3 & Psychroglacieae & 2 \\
\hline Limnohabitans & 2 & Alidiomarina & 8 & Nocardia & 4 & Bacteroides & 2 \\
\hline Delftia & 2 & Unculrured & 1 & Intestinimonas & 5 & Parabacteroides & 1 \\
\hline Oxalobacter & 1 & Roseovarius & 4 & Eubacterium & 2 & Prevotella & 2 \\
\hline Diaphorobacter & 0.9 & Tomitella & 2 & Faecalibacterium & 2 & Nocardia & 18 \\
\hline Polaromonas & 0.7 & Dietzia & 1 & Fourniella & 2 & Akkermansia & 4 \\
\hline Simplicispira & 1.6 & Galbitalea & 1 & Delfia & 1 & Bacillus & 1 \\
\hline Rhodocycla & 1 & Glaciibacter & 1 & Methyloversatilis & 1 & Intestinimonas & 1 \\
\hline Pseudomonas & 27 & Homoserinibacter & 1 & Accumulibacter & 1 & Thermoanaerobacter & 2 \\
\hline Acitenobacter & 3 & Leucobacter & 1 & Pseudomonas & 16 & Klebsiella & 1 \\
\hline \multirow[t]{8}{*}{ Other } & 27 & Sporosarcina & 19 & Alkanindiges & 3 & Escherichia-Shigella & 2 \\
\hline & & Hermiimonas & 5 & & 10 & Acidovorax & 1 \\
\hline & & Parapusilimonas & 4 & & & Accumulibacter & 1 \\
\hline & & Candidimonas & 6 & & & Pseudomonas & 8 \\
\hline & & Eoetvoesia & 1 & & & Lysobacter & 1 \\
\hline & & & 3 & & & & 10 \\
\hline & & Simplicispira & 1 & & & & \\
\hline & & Nitrosospira & 2 & & & & \\
\hline
\end{tabular}

\section{Acknowledgments}

This work is supported by Russian Foundation for Basic Research project № 20-05-00602 A

\section{Reference}

Bargar J.R., Williams K.H., Campbell K.M. et al. 2013. Uranium redox transition pathways in acetate-amended sediments. PNAS 110(12): 4506-4511. DOI: 10.1073/ pnas. 1219198110
Kelly S.D., Kemner K.M., Carley J. et al. 2008. Speciation of uranium in sediments before and after in situ biostimulation. Environmental Science and Technology 42(5):1558-1564. DOI: 10.1021 /es071764i

Li L., Steefel C.I., Williams K.H. et al. 2009. Mineral transformation and biomass accumulation associated with uranium bioremediation at Rifle, Colorado. Environmental Science and Technology 43(14): 5429-5435. DOI: 10.1021/ es900016v
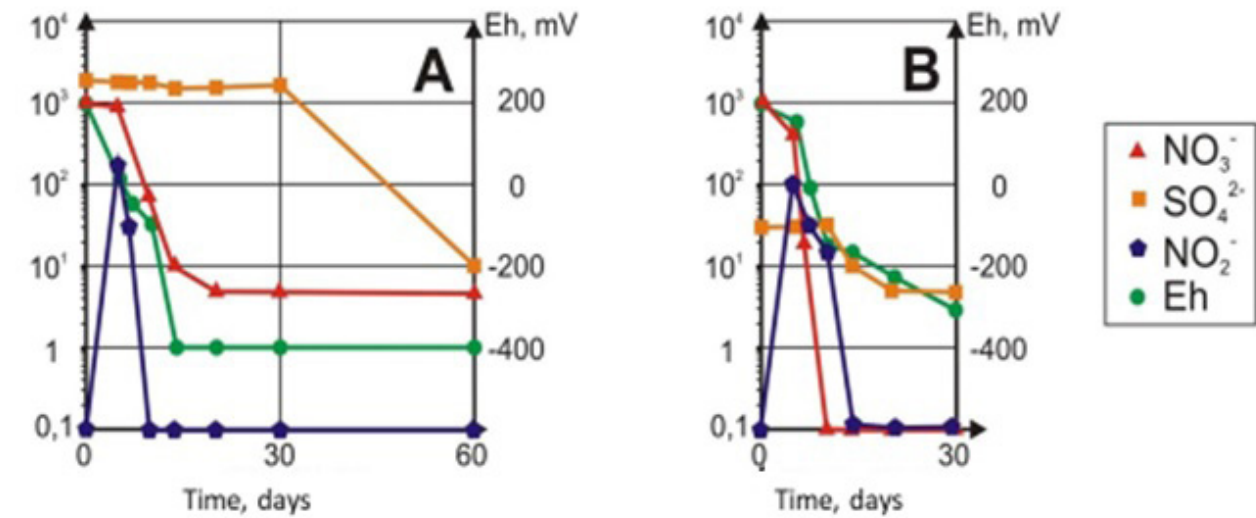

Fig. Laboratory bioremediation test results after sucrose treatment 